\title{
Un baile de la Palatina de Parma
}

\author{
EsTer Lidia CicCHETTI
}

Título: Un baile de la Palatina de Parma.

Resumen: El Baile de quien más ama forma parte del importante fondo de textos teatrales españoles de la colección CC*IV 28033 de la Biblioteca Palatina de Parma. Este estudio prentende dar a conocer un baile del Siglo de Oro anónimo y prácticamente desconocido, y sobre todo colocar la obrita en el contexto del baile como género literario, poniendo de relieve los rasgos constantes del género que la pieza de Parma presenta. Particular atención se reserva a la forma métrica del texto.

Palabras clave: Baile, Biblioteca Palatina de Parma, Edición crítica.

Fecha de recepción: 30/1/2013.

Fecha de aceptación: 15/3/2013.
Title: A Dance in the Palatina Library of Parma.

Abstract: The "Baile de quien más ama" is part of the important collection of Spanish dramatic texts (CC*IV 28033) guarded in Biblioteca Palatina of Parma. Its analysis pretends to make know an anonymous and unknown Golden Age text, placing it in the context of the baile as literary genre, pointing out its constant characteristics which this short dramatic text presents. Special attention is reserved to the metric form.

Key words: Dance, Palatina of Parma Library, Critical Edition.

Date of Approval: 15/3/2013

El Baile de quien más ama se encuentra colocado al final de la comedia Celos sin saber de quién y satisfacción acaso, de Don Gabriel de Irazábal y Balandín, escritor de quien nada ${ }^{1}$ se sabe, y conservada en la Biblioteca Pala-

1 Repertorios bibliográficos consultados: Cayetano Alberto de la Barrera y Leirado, Catálogo Bibliográfico y Biográfico del Teatro Antiguo Español. Desde sus origenes hasta mediados del siglo XVII, Madrid, Gredos, 1969 (1860); Carmen Simón Palmer, 
tina de Parma, en la colección de piezas teatrales españolas $C C^{*} I V 28033$ (volumen 38.V) (mm. 220 x 160, 67 ff. n.n.). El volumen conserva diez comedias de diferentes autores, todas manuscritas, con excepción de la primera; y algunas páginas de la segunda que están impresas. La comedia es del siglo XVIII y Antonio Restori y Maria Paola Miazzi Chiari la atribuyen a Antonio Hurtado de Mendoza ${ }^{2}$. La comedia, en realidad, no puede ser de este autor porque la suya, que lleva el mismo título, difiere de la que se encuentra en Parma. En efecto, el nombre de los personajes y el argumento desarrollado son diferentes. En la obra de Hurtado de Mendoza la acción se desarrolla en Madrid y los personajes principales son: Leonor, Diego, Rodrigo y María. Leonor, amada por Diego, se enamora de un hombre (Rodrigo) que corría a caballo por el Prado, sin conocer su identidad. Rodrigo ama a la mujer (María) de un retrato que le envió su amigo y no sabe cómo descubrir quién es. María vive la misma situación de Rodrigo, mientras que Diego es rechazado por Leonor. Todos los personajes sienten “celos sin saber de quién”. Además, los padres de

Manuscritos dramáticos del Siglo de Oro de la Biblioteca del Instituto del teatro de Barcelona, Madrid, C. S. I. C., 1977; José Simón Díaz, Bibliografía de la literatura hispánica, Madrid, C. S. I. C., 1995; Harold G. Whitehead, Short - Title Catalogue of Eighteenth century Spanish Books in the British Library, London, The British Library, 1994; Valentine Fernande Goldsmith y Kent Folkestone, A Short - Title Catalogue of Spanish and Portuguese Books, 1600 - 1700, in the Library of British Museum (the British Library - Reference Division), London, Dawsons of Pall Mall, 1974; Francisco Aguilar Piñal, Bibliografia de autores españoles del siglo XVIII, Madrid, C. S. I. C., Instituto Miguel de Cervantes, 1981, I-10; Francisco Aguilar Piñal, Sevilla y el teatro en el siglo XVIII, Oviedo, Universidad de Oviedo, 1974; Emilio Cotarelo y Mori, Colección de entremeses, loas, bailes, jácaras y mojigangas desde fines del siglo XVI a mediados del XVIII, Madrid, Bailly - Bailliére, 1911; Gaspar Merino Quijano, Los bailes dramáticos del siglo XVII, tesis doctoral, Universidad Complutense, 1981, 2 vols.; Indice Biográfico de España, Portugal e Iberoamérica, München, etc., Saur, 1990; María Teresa Cacho, Manuscritos hispánicos de las Bibliotecas de Parma y Bolonia, Kassel, Reichenberger, 2009, pp. 67-68. Antonio Restori publicó el baile en el artículo "Fragments de theatre espagnol", Revue de Langues Romanes, I (1898), pp. 141-147.

2 Antonio Restori, "La collezione CC*IV 28033 della Biblioteca Palatina Parmense", en Studi di Filologia Romanza, VI, Roma, 1891, pp. 65-66; y Maria Paola Miazzi Chiari, I manoscritti teatrali spagnoli della Biblioteca Palatina di Parma. La collezione CC*IV 28033, Parma, Tipolitografia Ghiaini, 1995, p. 39. 
Diego y María quieren casarlos contra su voluntad. La pieza termina con la decisión de Leonor, que opta por matrimoniar con Diego después de ser rechazada por Rodrigo, el cual se reúne con María ${ }^{3}$.

Por el contrario, en la comedia de Irazábal la acción se desarrolla en Salamanca y los protagonistas son Leonor, Félix, Isabel y don Juan. Este siente "celos sin saber de quién" porque una noche vio salir de la casa de su amada a dos hombres: don Félix y don Carlos. El primero es hermano de Leonor y cada noche va a ver a su padre, amén de esconderse por haber herido a don Carlos, que ahora quiere vengarse. Después de varios acontecimientos, la comedia termina con todos los personajes reencontrados en casa de Isabel, amiga de Leonor. Aquí don Félix le revela a Isabel todo su amor, contándole que nunca se había ido de Salamanca y que cada noche iba a ver a su padre. Don Juan lo escucha todo, pero, no satisfecho, habla también con don Carlos que le explica la razón de su presencia en casa de Leonor aquella noche. Al final todos los personajes se reconcilian.

No se conocen otros testimonios que transmitan la pieza breve $e^{4}$ Su autor es anónimo, o mejor, no sabemos si es el mismo que escribió la comedia porque no hay ninguna indicación al respecto en el códice. Además, el baile está transcrito con tinta y grafía diferentes respecto a la comedia, y no se puede excluir la hipótesis de que fuera acoplado a la comedia en un segundo momento por algún autor, vista la procedencia teatral de muchos manuscritos de Parma.

El baile ocupa cuatro hojas y no tiene relación temática con la comedia. En esta la acción se reduce a un equívoco que produce en los personajes "celos sin saber de quién" . Por el contrario, en el baile los protagonistas dan lugar a un diálogo sobre una cuestión amorosa, o sea, si es mejor el amante que declara su sentimiento o el que lo calla, sin llegar a una conclusión definitiva.

3 Gareth Alban Davies, A Poet at Court: Antonio Hurtado de Mendoza (1586-1644), Oxford, The Dolphin Book, 1971, pp. 256-260.

4 He realizado una investigación directa en la siguientes instituciones: la Biblioteca Nacional de Madrid, la Real Academia de la Lengua Española, la Real Academia de la Historia Española y la Biblioteca Municipal de Madrid.

5 La expresión "celos sin saber de quién" se encuentra también en la comedia de Tirso de Molina "Amar por señas" (II, escena 9) y en otra de Pedro Calderón de la Barca, "Casa con dos puertas mala es de guardar" (II, escena 14). 


\section{El BAILE COMO GÉNERO DRAMÁTICO}

Es oportuno situar la pieza en el contexto del baile como género literario. El baile es un tipo de pieza de teatro breve que, junto al entremés, la jácara y la mojiganga, era parte del conjunto de la fiesta teatral del Siglo de Oro. Gozó de gran éxito, tanto que en el siglo XVIII se fueron representando todavía muchos bailes de la centuria anterior. El género se desarrolló llegando a formas complejas, pero presenta rasgos constantes. Escrito siempre en verso, es más breve y simple que el entremés ${ }^{6}$. La situación normal es que tenga entre 70 y 190 versos: nuestro baile responde a esta característica, pues alcanza un total de 171 .

Un útil instrumento para quien estudia teatro breve es la Bibliografía descriptiva del teatro breve español de Agustín de la Granja y María Luisa Lobato $^{7}$, que ofrece una rica información y al mismo tiempo prueba que el baile es el género dramático menos estudiado.

Algo específico sobre este género se encuentra en la tesis doctoral de Gaspar Merino Quijano Los bailes dramáticos del siglo XVII y en su artículo El baile dramático: sus cuatro integrantes'. En estos trabajos, Merino Quijano pretende individuar los rasgos comunes del género, analizando un corpus de doscientas piezas. Es un análisis útil que puede ser tomado como punto de referencia para incluir nuestro baile en el contexto del género. Merino explica que el baile está formado por cuatro "integrantes": hablado, musical, cantado y bailado, es decir, recitación, música, canto y danza. Son elementos que caracterizan también los demás géneros menores, pero la diferencia se encuentra en su forma y distribución ${ }^{10}$.

Nuestra pieza se encuadra perfectamente en el género, ya que se caracteriza por la presencia de estos cuatro elementos fundamentales. Por lo

6 Rita Goldberg, "Un modo de subsistencia del romancero nuevo. Romances de Góngora y Lope de Vega en bailes del Siglo de Oro", en Bulletin Hispanique, 72, 1-2 (1970), pp. 56-95.

7 Aguastín de la Granja y María Luisa Lobato, Bibliografía descriptiva del teatro breve español (siglos XV-XX), Madrid, Iberoamericana; Frankfurt am Main, Vervuert, 1999.

8 Gaspar Merino Quijano, op. cit.

9 Gaspar Merino Quijano, "El baile dramático: sus cuatro integrantes", en Segismundo, 18, 39-40 (1984), pp. 51-71.

10 Gaspar Merino Quijano, op. cit., p. 51. 
que se refiere a la recitación, esta constituye precisamente la mitad de la obrita (84 versos en total), en alternancia con las partes cantadas y bailadas, que, juntas, representan la otra mitad (86 versos en total). Merino Quijano aclara que ningún baile fue cantado o bailado por completo, y que la extensión de la parte hablada varía en cada caso ${ }^{11}$. En nuestro baile, el recitado está formado exclusivamente por el diálogo (vv. 1-10, 39-83, 88-89, 120-121, 126-151), aunque el género admite también la forma del monólogo ${ }^{12}$. Es introducido por las acotaciones Recitado o Representa$d o$ (v. $1 \infty$, v. $39+$, v. $68+$, v. $88+$, v. $120+$ ).

En cuanto a la música, no se conserva, y la única referencia presente en el texto figura en la acotación inicial:

Salen cuatro zagales, el uno de ellos ha de ser una música, y ha de salir con sombrerillo o montera con plumas, y ha de salir Anfriso que lo ha de hacer la música como desasosegado.

Quijano afirma que el integrante musical va siempre unido al canto; carece de independencia porque su tarea es la de realizar y cambiar la mímica, es decir, el baile ${ }^{13}$. La música o músicos eran fundamentales para una compañía teatral y había actores especializados en estos ámbitos. Según el análisis del mismo estudioso, los músicos podían presentarse de diferentes maneras: al principio del baile para introducir el argumento, entre los personajes o como personajes dramáticos ${ }^{14}$.

Por lo que se refiere al canto, destaca en toda la pieza en alternancia con las partes recitadas. Las partes cantadas no son bailadas, pero todas las bailadas son cantadas. En efecto, el final del baile se caracteriza por la presencia de una suerte de danza que es al mismo tiempo cantada (vv. 152-171). Como ocurría con los recitados, el canto es introducido muy a menudo por acotaciones específicas como Canta, cantado etc. (v.11+, v. $84+$, v. $90+$, v. $122+$, v. $152+$ ); pero, otras veces, estas están involucradas implicítamente en el texto; dos procedimientos muy comunes en el

11 Ibidem.

12 Gaspar Merino Quijano, Los bailes, p. 176.

13 Gaspar Merino Quijano, "El baile", p. 53.

14 Gaspar Merino Quijano, op. cit., pp. 54-57. 
género $^{15}$ :

-vv. 9-10, Anfriso... al viento daré mis voces / Los tres Zagales A tu voz atenderemos.

-v. 68, DAMA $1^{\circ}$ Prosigue lo que cantabas.

-vv. 72-73 DAMA $1^{\circ} \ldots$ de tan dulces suspenciones / de tan acordados quiebros.

-v. 89, Marcia Atended a mis acentos.

-v. 133, ANFriso ... ha de publicar mi acento.

-v. 135, Marcia ... he de dar la voz al viento.

Según el análisis de Quijano, el integrante cantado puede aparecer al comienzo, por el medio o al final de la pieza, en diferente proporción, produciendo, de esta manera, gran movilidad y flexibilidad ${ }^{16}$.

La danza irrumpe al final de la obra (vv. 152-171) y bailan todos los personajes. Como acaecía en los demás componentes, también la danza es introducida por una acotación (152+), donde se dan informaciones técnicas; pero, al mismo tiempo, es presentada también a través de las palabras de los personajes, que piden expresamente que se ejecute:

-v. 130, DAMA $1^{\circ}$ Mejor será que en un baile...

-vv. 136-137, DAMA $2^{\circ}$ Pues empecemos el baile / que se está perdiendo tiempo.

-v. 150, Marcia Y así empecemos el baile.

El texto se acomoda a la danza a través de algunos recursos estilísticos, según técnicas frecuentes en el género ${ }^{17}$. Es lo que ocurre en los versos finales de la obrita, donde el v. 152 funciona como estribillo, ya que se repite ligeramente variado en el v. 156; también hay una serie de repeticiones en las demás coplas (El que, vv. 160, 164; pues, vv. 162, 166). El integrante bailado es, según Quijano, el más importante, por no decir indispensable, mientras que en los demás géneros menores, como el entremés, no resultaba necesario. En este caso también se puede hablar de movilidad y flexibilidad, porque el baile puede aparecer al comienzo, en

15 Gaspar Merino Quijano, Los bailes, pp. 177-182.

16 Gaspar Merino Quijano, “El baile”, pp. 58-60.

17 Gaspar Merino Quijano, Los bailes, pp. 231-244. 
el medio o al final de la pieza, aunque sea más frecuente esta última opción. Puede ser bailado por todos los personajes, o sólo por tres o cuatro ${ }^{18}$.

Por lo que se refiere a dichos integrantes, no se pueden jerarquizar, ya que se completan en una unidad. La belleza de la pieza reside en la estructura plástica y espectacular de su conjunto. Los mismos integrantes figuran también en otros géneros del teatro breve, sobre todo el entremés. La diferencia entre los dos géneros consiste en la forma y distribución de las partes recitadas y cantadas, porque en el baile tienen que ser perfectamente amalgamadas. De hecho, la falta de esta fusión nos llevaría al terreno del entremés. En este, el baile se encuentra al final de la pieza, mientras que en nuestro género hay un desarrollo paralelo de texto, canto, música y mudanzas ${ }^{19}$. A pesar de todo, baile y entremés traban una relación muy estrecha, tanto es así que Merino Quijano llega a afirmar que el entremés es el precedente más importante del baile y que la presencia de la danza en el entremés parece explicar el origen del baile, como género dramático. De esta manera, se podrían explicar las coincidencias de rasgos y fundar las clasificaciones intermedias: entremés cantado o baile entremesado ${ }^{20}$. Sin embargo, la linde entre los dos géneros no es muy nítida, aunque el estudioso propone una definición según la cual cuando en el baile "la parte hablada se incorpora con canto y danza, entrecruzándose en la pieza, en una unidad armónica y constitutiva, y desarrollando al mismo tiempo una acción argumental y personajes dramáticos, la pieza logra plenitud estructural como género" ${ }^{21}$.

En virtud del examen de estos ingredientes, el especialista distingue tres momentos evolutivos en la historia del baile:

-Comienzo: fin del siglo XVI-1620. La música y el baile son los elementos principales del género, mientras que el texto cantado y recitado es un mero soporte.

-Auge: 1620-1660. Hay unidad armónica entre los cuatro integrantes.

-Decadencia: a partir de 1660-1670. Música y baile prevalecen otra vez sobre el texto cantado y recitado ${ }^{22}$.

18 Gaspar Merino Quijano, "El baile”, pp. 60-69.

19 Gaspar Merino Quijano, Los bailes, pp. 158-159.

20 Gaspar Merino Quijano, op. cit., pp. 163-165.

21 Gaspar Merino Quijano, "El baile” cit., p. 52.

22 Gaspar Merino Quijano, op. cit., pp. 51-71. 
Por lo que se refiere a la decadencia del género, Susana Antón, en su estudio sobre la función de la música y la danza en el teatro breve, explica que "los cambios que muestra el teatro breve después de 1650 no se deben a una cuestión de decadencia, sino que son producto de un mayor número de importantes factores político-sociales"23.

En efecto, a partir de 1650, con la boda de Felipe IV y Mariana de Austria, la corte regresó a los grandes festejos, pero la actividad teatral se traslada de la ciudad al palacio real. Por lo tanto el teatro breve experimenta varios cambios, en temas, personajes y lenguaje: pierde su tono crítico y satírico, su costumbrismo y realismo para acercarse a lo alegórico, mitológico y pastoral. Ahora los personajes son, casi siempre, pastores idealizados o seres alegóricos y mitológicos que pierden su carácter ridículo en función de alabanza a la familia real. En palabras de Susana Antón:

... estos intermedios pasaron a representarse en un espacio de características peculiares -el teatro real- en el que imperaban unas normas de comportamiento muy específicas -las Etiquetas de Palacio-, siendo dirigidos a un público particular -los cortesanos-; los mismos, además, eran organizados para una ocasión específica -las celebraciones de la familia real- y tenían como autores, en su gran mayoría, a músicos o escritores que trabajaban para la corte ${ }^{24}$.

La música, en este momento, empieza a cobrar un papel fundamental y no se encuentra sólo en la parte final de la pieza ${ }^{25}$.

La palabras de Antón bien se pueden aplicar a nuestro baile. En efecto, la pieza parece pertenecer al entorno de la corte, sus personajes son zagales idealizados y el lenguaje pertenece a la lírica amorosa con fuertes huellas petrarquistas. No hay nada de realismo o costumbrismo y el componente cómico es muy reducido (vv. 141-151).

Desde un punto de vista temático, como ya se ha apuntado, la pieza se centra en una cuestión amorosa que queda sin resolver. De hecho, se

23 Susana Antón Priasco, Música y danza en el teatro breve español representado en la corte entre 1650 y 1700. Análisis de su función en entremeses, bailes drámaticos y mojigangas, conservados en la Biblioteca Nacional de Madrid, tesis doctoral, Universidad de Oviedo, 2001, 2 vols., pp. 5-10.

24 Ibidem.

25 Ibidem. 
caracteriza por una dramaticidad muy reducida: los personajes no actúan, se plantea un caso, un problema, pero no se llega a su solución, no cambia nada respecto al comienzo. Tampoco los demás personajes, damas y zagales, apenas hacen nada, siendo su única función la de introducir el canto de los protagonistas, Marcia y Anfriso, a través de sus continuas peticiones. Además, estos personajes secundarios nunca cantan, aunque, como se indica en la última acotación, son importantes para la coreografía del baile final:

Pónense en dos a dos o interpolados zagales y damas, o como fuere necesario para el baile; y cantará la primera copla Marcia, la 2 Anfriso, la 3 Marcia, la 4 Anfriso y la 5 los dos en dúo, y entre medio de copla y copla danzarán la tocata de las coplas.

El texto literario y la cuestión amorosa desarrollada parecen ser un mero pretexto para que los personajes canten y bailen. Desde este punto de vista, podría pertenecer a la época más tardía del género, ya que música y danza prevalecen sobre el texto.

Finalmente, hay que subrayar cómo en la aparición de damas y zagales se percibe también cierta simetría que, como se verá, modula toda la pieza. De hecho, los dos protagonistas están rodeados por el mismo número de personajes (cuatro cada uno), y, además, vestidos de la misma manera. Todos llevan un sobrero o una montera con plumas, un hecho que prueba que también el vestuario desempeña un papel fundamental en la convergencia de todos los aspectos de la representación.

\section{ESTRUCTURA Y FORMA MÉTRICA}

Merino Quijano afirma que el baile se caracteriza por una gran movilidad y variabilidad métricas. Explica también que el género, respecto al entremés (en el cual domina casi siempre un 'tipo' métrico), 'tiende a plasmarse en 2-6 combinaciones métricas distintas [...] que se extienden en más abundantes pasajes en un marco muy abierto y libre de posibilidades" 26 .

Entre las formas métricas que poseen la primacía figuran el romance, la

26 Gaspar Merino Quijano, Los bailes, pp. 261-262. 
seguidilla, los pareados, la redondilla y las formas irregulares, todas estructuras que se combinan perfectamente con el canto y el baile. Las formas irregulares suelen aparecer donde hay música, canto y baile. Según el estudioso, el aparente desorden métrico no es deformación, sino libertad de variación estrófica y exigencia musical. En efecto, la música elimina las posibles irregularidades. Por lo que se refiere a la seguidilla, él la define como el alma mater del baile y motor de todas sus combinaciones ${ }^{27}$.

Merino Quijano observa, además, que el baile se caracteriza por la rima asonante, que ocupa el 60-80\% de los versos y corresponde al romance. Los versos asonantados tienen libertad de colocación, pero parte de ellos suele aparecer al principio. En nuestro caso la asonancia cobra un papel fundamental, porque siempre enlaza las partes cantadas con las recitadas (vv. 10-12, 38-40, 83-85, 86-89, 89-91, 119-121, 121-123, 125-127). Eso no ocurre en el corpus examinado por Merino Quijano, ni en los textos recogidos por Emilio Cotarelo y Mori y Javier Huerta Calvo en sus antologías. La función expresiva de este rasgo, por lo visto no muy común, se antoja por otra parte evidente.

Merino Quijano nos describe también la estructura métrica típica del género: "breve presentación en romance (tiradas de 10 a 40-60 versos: variabilidad) + seguidilla + breve pasaje en romance (presentación de cada personaje con su problema) + seguidilla (respuesta comentario al mismo...) '28. Con la excepción de la primera sección en romance, se observa una alternancia breve de romance y seguidilla. Esta suele aparecer al final de la pieza ${ }^{29}$.

La estructura métrica del Baile de quien más ama presenta todos estos rasgos, pero el aspecto más importante es su simetría, tanto en lo formal como en lo temático. En efecto, el texto empieza con una parte recitada en romance, en la cual los zagales, a través del diálogo, introducen el argumento de la pieza: el sufrimiento amoroso de Anfriso (vv. 1-10). Sigue una parte cantada, correspondiente a los vv. 11-38. Se trata de un monólogo en el que Anfriso da rienda suelta a todo su dolor, y donde se encuentran todos los recursos útiles para acomodar el texto a la música, por ejemplo las exclamaciones $(A y)$, las figuras de repetición (anáfora en

27 Gaspar Merino Quijano, op. cit., pp. 260-274.

28 Ibidem, p. 277.

29 Ibidem, pp. 275-280. 
los vv. 19, 21, 23 y 31-34) o el estribillo que se repite al principio y al final de la tirada (vv. 11-14 y 35-38). El canto de Anfriso está formado por dos cuartetos iniciales, el primero de tres endecasílabos y un heptasílabo, caracterizado por la misma asonacia $(e-o)$ de la anterior parte recitada; y el segundo de endecasílabos con rima consonante (ABBA); siguen un pareado de endecasílabos, una décima de endecasílabos y heptasílabos (abbaaCCddC), otra serie de pareados (heptasílabos) y un cuarteto final que repite el del principio, enlazándose, otra vez, con la siguente parte recitada gracias a la misma asonancia. Por lo que atañe a la letra, el canto de Anfriso se caracteriza también por la presencia de imágenes petrarquistas como el prisionero de $\operatorname{amor}^{30}$ (vv.12 y 36) o la mariposa (v. 27), que siempre indica el amante "revoloteando en pos de la amada"31. Además, en el v. 22 ("que adore un imposible") se percibe también la huella de una canción ya conocida y que figura en obras de Calderón ${ }^{32}$.

Después del monólogo cantado se incluye una larga parte recitada, toda en romance (vv. 39-84), y una seguidilla simple cantada por Marcia (vv. 84-87), que mantiene una vez más la misma asonancia del diálogo precedente. En esta larga tirada se desarrollan el diálogo entre los zagales y Anfriso, y se explica por qué no quiere declarar su amor; y otro diálogo simétrico entre Marcia y las zagalas, con la presentación de la protagonista.

Sigue otra parte cantada, esta vez un monólogo de Marcia, en el que describe su concepción del amor (vv. 90-119). Estos versos son métricamente idénticos a los que formaban el canto de Anfriso y la asonancia cobra el mismo papel de puente entre las partes cantadas y recitadas: dos cuartetos iniciales, el primero de endecasílabos y heptasílabos asonantes $(e-o)$ y el segundo de endecasílabos con rima consonante (ABBA), un pareado de endecasílabos, una décima de endecasílabos y heptasílabos (abbaaCCddC), una seguidilla simple, un pareado de heptasílabo y endecasílabo, y el cuarteto final que repite el del principio. Como ya se ha explicado, los cuartetos iniciales y finales se caracterizan por la misma

30 María del Pilar Manero Sorolla, Imágenes petrarquistas en la lírica española del Renacimiento, Barcelona, PPU, 1990, pp. 134-142.

31 Ibidem, pp. 313-317.

32 Edward M. Wilson - Jack Sage, Poesías líricas en las obras dramáticas de Calderón, London, Tamesis, 1964, p. 48. 
asonancia del romance de las partes recitadas, de modo que estas resultan enlazadas al canto. El único punto en que los dos monólogos difieren es después de la décima, porque en el canto de Marcia irrumpe una seguidilla en lugar de los pareados. El monólogo de la protagonista femenina se perfila por la presencia de imágenes petrarquistas, tales como las flechas de $\operatorname{amor}^{33}$ (vv. 92 y 118) y la descripción del amor como áspid ${ }^{34}$ tirano (v. 101) y $\operatorname{traidor}^{35}$ (v. 103).

Al canto de Marcia (vv. 90-119) sigue otra parte recitada en romance (vv. 120-151) y el baile termina con una serie de seguidillas reales, cantadas por Marcia y Anfriso y bailadas por todos los personajes.

Como en el monólogo de Anfriso, que presenta huellas de una canción preexistente, también en la intervención de Marcia se aprovecha una canción ya conocida y que consta también en varias obras de Calderón. Es lo que ocurre en los vv. 122-123 ("Sólo el silencio testigo / ha de ser de..." $)^{36}$. Las únicas diferencias respecto al monólogo de Anfriso consisten en el hecho de que aquí la cita de la canción es más evidente, mientras que la anterior es sobre todo el recuerdo del lugar común del "adorado imposible" 37 ; y en que no se encuentra en el monólogo cantado por Marcia, sino en una seguidilla (de todas formas cantada por ella), que asoma después de su monólogo, pero separada del mismo por la breve intervención de Anfriso (vv. 122-125).

En resumen: en nuestro baile se registran cinco formas métricas diferentes, que distinguen las partes cantadas y recitadas, por otra parte enlazadas por la asonancia. En los versos recitados sólo se utiliza el romance (con asonancia constante $e-o$ ), mientras que los versos cantados se caracterizan por su variedad métrica. Hay cuartetos de endecasílabos con rima consonante (ABBA) y otros con asonancia y la inserción de un heptasílabo. Se utiliza también el pareado, y en varias combinaciones (sólo endecasílabos, sólo heptasílabos o en alternancia de endecasílabos y heptasílabos). Se encuentran seguidillas simples (vv. 84-87, vv. 110-113) y reales (vv. 160-171). Estas caracterizan el final

33 María del Pilar Manero Sorolla, op. cit., pp. 103-118.

34 Ibidem, pp. 279-290.

35 Ibidem, pp. 125-134.

36 Edward M. Wilson - Jack Sage, op. cit., pp. 124-125.

37 Ibidem, p. 48. 
del baile. Todos los versos están ligados por rima o asonancia; no hay versos blancos. En las partes cantadas se halla la repetición de versos idénticos, con el valor de estribillos: es éste el caso de los vv. 11-14 y 90-93, que corresponden respectivamente a los vv. 35-38 y 116-119. Tal identidad debía tener su paralelo en la música que acompañaba a la ejecución.

Podemos esquematizar así la métrica de la pieza:

$\begin{array}{ll}\text { vv. 1-10 } & \text { Romance (e - o) } \\ \text { vv. 11-14 } & \text { Cuarteto (3 endecasílabos y un heptasílabo con asonancia } e \text { - o) } \\ \text { vv. 15-18 } & \text { Cuarteto de endecasílabos (ABBA) } \\ \text { vv. 19-20 } & \text { Pareado de endecasílabos } \\ \text { vv. 21-30 } & \text { Décima de endecasílabo y heptasílabos (abbaaCCddC) } \\ \text { vv. 31-34 } & \text { Pareado de heptasílabos } \\ \text { vv. 35-38 } & \text { Cuarteto (3 endecasílabos y un heptasílabo con asonancia e - o) } \\ \text { vv. 39-83 } & \text { Romance (e - o) } \\ \text { vv. 84-87 } & \text { Seguidilla simple (e-o) } \\ \text { vv. } 88-89 & \text { Romance (e - o) } \\ \text { vv. 90-93 } & \text { Cuarteto (3 endecasílabos y un heptasílabo con asonancia e - o) } \\ \text { vv. 94-97 } & \text { Cuarteto de endecasílabos (ABBA) } \\ \text { vv. 98-99 } & \text { Pareado de endecasílabos } \\ \text { vv. 100-109 } & \text { Décima de endecasílabos y heptasílabos (abbaaCCddC) } \\ \text { vv. 110-113 } & \text { Seguidilla simple (e-o) } \\ \text { vv. 114-115 } & \text { Pareado de heptasílabo y endecasílabo } \\ \text { vv. 116-119 } & \text { Cuarteto (3 endecasílabos y un heptasílabo con asonancia } e-o \text { ) } \\ \text { vv. 120-151 } & \text { Romance (e - o) } \\ \text { vv. 152-171 } & \text { Seguidilla real (se alternan endecasílabos y hexasílabos con } \\ \text { asonancia, é) } & \end{array}$

Cabe decir que la métrica no siempre es regular, puesto que se han detectado algunas imperfecciones (vv. 95-96; 104; 156; 169-171), que no se han enmendado, ya que las soluciones podrían ser múltiples. Sin embargo, considero que la música y el canto hacían más aceptables y, quizás imperceptibles, estas irregularidades.

Finalmente, hay que subrayar otro rasgo de la pieza: el juego de simetrías y paralelismos que domina su estructura. En efecto, el baile responde a una geometría precisa. Se puede dividir en tres partes: las dos primeras, perfectamente simétricas, y la conclusión. 
La primera se caracteriza por unos versos recitados (vv. 1-10), que cjmplen la función de introducir el canto de Anfriso (11-38). Después de este monólogo cantado figuran otros versos recitados (vv. 39-67), con el diálogo entre los zagales y Anfriso.

La segunda presenta el mismo esquema. Empieza con una serie de versos recitados (vv. 68-89), que, en perfecta simetría con la primera parte, introducen el canto de Marcia (vv. 90-119). En este caso, figura una seguidilla cantada (vv. 84-87), que, desde un punto de vista temático, forma un conjunto con los versos recitados. Sigue el monólogo cantado por la protagonista, simétrico al de Anfriso, y otro grupo de versos recitados (120-151) ocupados por el diálogo entre los personajes. La única diferencia consiste en el hecho de que esta serie de versos es más larga y, sobre todo, intervienen casi todos los personajes. De todas formas, estas disparidades asumen la tarea de introducir la conclusión de la pieza (vv. 153-167), caracterizada por la presencia en escena de todos los personajes y por la unión armónica de todos los elementos que articulan el baile (música, texto, canto y danza).

También desde el punto de vista temático la obra responde a este juego simétrico, ya que las intervenciones de los dos protagonistas se presentan como una disputatio sobre un asunto muy trillado, que se remonta a la literatura cortés: el contraste del amante entre celarldeclarar su amor. El celar constituía una regla fundamental en la ideología cortesana, ya que el galán que declaraba sus intenciones ofendía a la dama y se convertía en villano (principio enunciado por el mismo Anfriso, vv. 64-65). El tema fue muy productivo en la literatura cortés ${ }^{38}$, confluyendo, en España, en la poesía cancioneril y en la novela sentimental ${ }^{39}$, hasta llegar a la formulación de una pauta anticortés en la Celestina,

38 Sobre este tema cf. Jeanne Battesti-Pelegrin, "Decir / Callar: reflexiones sobre un motivo cancioneril", en Actas del II Congreso internacional de la Asocición Hispánica Medieval (Segovia, 15-19 de Octubre de 1987), eds. J. M. Lucía Megías, P. Alonso, C. Martín Daza, Alcalá de Henares, Universidad, 1992, I, pp. 187-202; Pierre Le Gentil, La poésie lyrique espagnole et portugaise a la fin du Moyen Age, Rennes, Plihon, 1949-1953; Mario Mancini, "La lode e il segreto. Sul motivo del "celar»", en Metafora feudale. Per una storia dei trovatori, Bologna, Il Mulino, 1993, pp. 187-205.

39 Antonio Gargano, “"Son joi celar»: segretezza d'amore e desiderio d'esibizione nella Celestina”, en Rivista di Filologia e Letterature Ispaniche, I (1998), pp. 9-46. 
donde, según Gargano, el tema se utiliza bajo una nueva perspectiva humanístico - renacentista ${ }^{40}$.

En nuestro texto se vuelve a proponer el mismo debate: Anfriso y Marcia se enfrentan sobre este topos, y en el centro de sus intervenciones se alza el contraste simétrico entre publicar / callar y el sentimiento amoroso. Bien mirado, y a pesar de la ambientación mitológico-pastoril, el desarrollo es el de la quaestio filosófica medieval, un proceso todavía muy vital en la práctica académica española. El casus corresponde a la oposición silenciolconfesión del amor; Anfriso y Marta desempeñan el papel de discípulos, alternando las argumentaciones en favor de cada opinión, con imágenes y motivos característicos de la literatura cortés; pero, como se ha dicho, falta la solución final, "dejada" "para otra vez" (vv. 168-169). El carácter de quaestio que tiene el baile se percibe también en ciertos pasajes lógicos, como cuando Anfriso subraya las contradicciones en las cuales incurrió su amada (vv. 126-127).

Además, el juego de simetrías que caracteriza la estructura de la pieza, según se ha explicado, tiene su paralelo en la forma métrica, ya que todas las partes recitadas están en romance y los dos monólogos cantados se construyen sobre la misma forma métrica. La convergencia entre todos los componentes teatrales y dramáticos debía producir en las tablas la coherencia absoluta de la pieza, coherencia que, al faltarnos la música, podemos apreciar sólo parcialmente.

\section{CRITERIOS DE TRANSCRIPCIÓN}

En la trascripción del texto se sigue un criterio de modernización general de la grafía, la puntuación y la separación de palabras.

Respecto a la edición de Restori, transcribimos con más exactitud las acotaciones, y damos cuenta con más escrúpulo de las tachaduras.

40 Ibidem, pp. 25-39. 
BAILE DE QUIEN MÁS AMA, EL QUE DICE SU AFECTO O EL QUE LO CALLA

\section{Cuatro zagales, Cuatro damas.}

Salen cuatro zagales, el uno de ellos ha de ser una música, y ha de salir con sombrerillo o montera con plumas, y ha de salir Anfriso que lo ha de hacer la música como desasosegado.

\section{Recitado}

ZAGAL $1^{\circ}$

Anfriso, dinos qué tienes.

ANFRISO

No es posible, que no encuentro

razones para explicar

el mal que en el alma siento.

ZAGAL $2^{\circ}$

El persuadirte lo digas

es por ver si hallamos medio

con que poder consolarte.

ANFriso Sólo por obedeceros

al viento daré mis voces.

LOS TRES ZAGALES A tu voz atenderemos.

Canta Anfriso lo siguiente

ANFRISO

¡Ay de mí, infeliz y sin fortuna, que de amor prisionero, al horroroso estrago de sus iras víctima yace el corazón sangriento!

Esta pasión, que el alma me atormenta, la siento como halago y es veneno; este dolor, con que incesante peno, es un hechizo que halagarme intenta; y de males y bienes acosado, vivo muriendo a influjo de mi hado.

Y pues amor ordena

que adore un imposible, 
y este ardor insufrible

el alma me enajena, sea el llanto en tal pena

intérprete que diga a Marcia hermosa

que sus desdenes rondo mariposa,

y que al rigor severo

de su entereza muero,

diciendo en la postrera ansia forzosa,

con insufrible acento,

y con triste lamento,

con rabia, con furor,

con pena, con dolor:

“Ay de mí, infeliz y sin fortuna;,

que de amor prisionero,

al horroroso estrago de sus iras

víctima yace el corazón sangriento”.

Representado

ZAGAL $1^{\circ}$

ANFRISO

ZAGAL $2^{\circ}$

ANFriso
Anfriso, ¿le has dicho a Marcia

alguna vez tus deseos?

No, porque es tan soberana

que aunque el corazón resuelto

alguna vez lo ha intentado,

cobarde ha excusado el riesgo.

Pues si tu amor no le has dicho,

¿por qué con tanto lamento

de sus rigores te quejas?

Aunque ser así confieso,

yo sé que mi amor no ignora,

50

porque deidad la contemplo

$y$, como es deidad, presumo

penetra mis pensamientos;

y en diversas ocasiones

la he explicado mis afectos

55

con la lengua de los ojos, 
y como siempre la atiendo

tan lejos de mi esperanza, que aun atención no la debo,

presumo que no premiarme

nace de aborrecimiento.

ZaGal $3^{\circ} \quad$ Pues ella sale, dila ahora

tu pena y tu sentimiento.

ANFrIso No me atrevo a declarar

por discurrir que la ofendo.

¡Mira qué hermosa que sale,

mira aquel garbo y aseo!

Salen cuatro damas con sombrerillos o monterillos de pluma y Marcia ${ }^{41}$. Los zagales quedan a un lado del tablado como hablando todos juntos y las damas al lado contrario.

Representado

DAMA $1^{\circ}$

DAMA $2^{\circ}$

MARCIA
Prosigue lo que cantabas

Marcia, que aunque en este puesto

concurran esos zagales,

70

no es justo nos priven ellos

de tan dulces suspensiones,

de tan acordados quiebros.

Todas te lo suplicamos.

Pues atended porque quiero

75

deciros quién es amor,

porque huyáis de sus afectos;

mas la que su orgullo rinda

a ese Dios todo embeleco,

explique su mal y diga

80

lo que siente allá en el pecho,

que el no hablar cuando le importa 


\section{Cantado}

para los mudos es bueno.

Y en fin, el que se hallare

su prisionero

con las voces procure

romper sus yerros.

\section{Representado}

DAMA $3^{\circ}$

MARCIA

Marcia, graciosa te ostentas.

Atended a mis acentos.

Canta Marcia

MARCIA

Oídme lo que es el amor zagalas,

90

porque de su veneno

advertidas podáis contra sus flechas

conseguir de sus armas el desprecio.

Es el amor una pasión vehemente

que arrastra imperiosa toda la razón;

es áspid bastardo que en el corazón

entra halagando, mas luego impaciente,

todo lo afable convierte en tirano,

ostentando soberbio lo inhumano.

$\mathrm{Y}$ pues veis que es amor:

aleve áspid tirano,

riguroso inhumano,

halagüeño y traidor,

el que padezca su ardor

publique su dolor y en sus razones

procure que se entiendan sus pasiones,

que el que su amor explica

su pasión sacrifica

y expone el corazón a los arpones;

que el que su amor no dice

poco amor tiene, 
porque el que no se queja

poco le duele.

Esto del amor siento,

y así para que se huya su tormento

oídme lo que es el amor zagalas,

porque de su veneno

advertidas podáis contra sus flechas

conseguir de sus armas el desprecio ${ }^{42}$.

Representado

ANFRISO

Dinos, Marcia, esa opinión,

¿es la que seguir debemos?

\section{Cantado}

MaRCIA

Sólo el silencio testigo

ha de ser de los afectos,

que a las deidades se sirve

sólo con los rendimientos.

Representado

ANFrISO

Pues, ¿`cómo, has aconsejado

lo contrario?

MARCIA

Porque tengo

razón para lo uno y lo otro.

ANFRISO

No lo alcanzo.

Marcia

Escucha atento.

DAMA $1^{\circ}$

Mejor será que en un baile se expliquen ambos conceptos.

ANFriso Del silencio las razones

ha de publicar mi acento.

MarCIA Pues por lo contrario yo,

$42 \mathrm{Al}$ lado de este verso aparece una tachadura ilegible. 
he de dar la voz al viento.

Dama $2^{\circ} \quad$ Pues empecemos el baile

que se está perdiendo tiempo.

ANFRISO

Primero quisiera, Marcia,

decirte que si merezco

ser de tus iras despojo...

MARCIA

Anfriso, de eso no hablemos.

ANFRISO

Si te agravia que te quiera

no te lo dirá mi afecto.

MARCIA

¡Lindo modo de callarlo

es advertirme del riesgo!

ANFRISO

Por mí no lo has de saber.

Marcia

Aunque lo digas te advierto,

que aun cuando quiero soy sorda:

¿qué seré cuando no quiero?

Y así empecemos el baile,

y entrega tu amor al viento.

Pónense en dos alas o interpolados zagales y damas, o como fuere necesario para el baile; y cantará la primera copla Marcia, la 2 Anfriso, la 3 Marcia, la 4 Anfriso y la 5 los dos en dúo, y entre medio ${ }^{43}$ de copla y copla danzarán la tocata de las coplas.

MarCIA Es el amante que su amor explica

atento y cortés,

porque en advitrio de su dama pone

favor o desdén.

Bailan

ANFriso Es el amante que su afecto no explica

discreto, porque

ama sólo sin tener esperanza

de más merecer.

43 En este punto, después de "medio", figura una tachadura, donde se lee "cada". 
Bailan

MarCIA El que dice sus ansias se ofrece

160 por esclavo fiel,

pues voluntario a otro dueño rinde toda su altivez.

Bailan

ANFrISO

El que oculta su pasión más fino

juzgo que ha de ser,

pues conserva en su pecho el incendio sin darlo a entender ${ }^{44}$.

Bailan

ANFriso y Marcia

IN DÚO

Demos fin a este baile, dejando

para otra vez

sin decidir cuál de entrambos afectos

170

el más fino es.

Bailan y dase fin.

44 El último verso de cada copla cantada y bailada por Marcia y Anfriso está subrayado. 